the base of the bladder, with a long beak we find it a difficult matter, but easy when we have the short beak of Thompson's sound. So there are several reasons why I prefer it.

In sounding the patient $I$ will first inject water into the bladder. Introducing the sound I detect a roughened condition of the walls of that organ, but I do not find anything else. I now pass my finger into the rectum, but still feel nothing. We now tip up the pelvis by placing a pillow under it, and thus have opportunity to examine the fundus of the bladder. A little blood issues, a result probably of the ulcerated condition of the neck of the bladder, which was caused by old urethritis. With the exception of this and the granular condition of its walls I find nothing abnormal.

Frost Bite. - Our next patient is a colored boy, who is the victim of a frost bite of a fortnight since. The feet are the parts affected. The lad was brought in one week ago in the condition which you now see. The toes show various degrees of injury, from the great toes, which are involved down to the bone, to the small toes, in which the cuticle alone seems affected. Some of them will cover and heal by granulation, but I think it best to remove the distal phalanges of the two large toes. I see the rnatrix of the nail is intact. I will then split the toe above and below the bone, take out the phalanx, and thus, as far as is possible, save the nail. The bone which $I$ have removed is long and flat. The tissue remaining will make a good stump. In the same manner we now treat the other big toe. The flaps are brought together with plaster.

\title{
CASES ILLUSTRATING THE WORK AND DUTIES OF THE MEDICAL EXAMINER. ${ }^{1}$
}

BY F. W. DRAPER, M. D.

WHEN I received the compliment of an invitation to read a paper on this occasion, it was suggested that a report of cases would be acceptable, illustrating some of the difficulties which a Massachusetts medical examiner meets in the performance of his duties under the requirements of the law of 1877. Acting upon this suggestion, I sought for material adapted to its fulfillment; but while I found considerable evidence that the difficulties described had actually occurred, an impartial scrutiny, showed that these mainly grew out of inexperience and maladroitness in a novel field of duty. In truth, Mr. President, this single year's record compels the conviction that the Massachusetts law of 1877 concerning medical examinations and inquests in cases of death by violence presents few and comparatively insignificant defects and difficulties to any one who recognizes the purpose of the statute and means hon-

1 Read before the Massachusetts Medico-Legal Society, June 11, 1878. 
estly and conscientiously to execute it. I think the testimony will be concurrent that the law has had exceptional and gratifying success as a new and in a measure experimental piece of legislation. After further trial, experience may show that modifications may be made which shall mend without marring; meanwhile our society is to be congratulated that the general disposition at present is favorable to a fair test of this Massachusetts plan.

I shall be pardoned, therefore, if I feel disinclined to make an exposure of my own short-comings as a medical examiner. Let me address myself to a more congenial task. From the records of the year I have selected the notes of three cases which, on account of their somewhat remarkable character, serve to illustrate, not the defects of the new law, but some of its manifest advantages and capabilities of usefulness. These cases are as follows :-

I. Martin C., a robust and vigorous Irishman, thirty-three years old, came to his death under the following circumstances: $\mathrm{He}$ arose as usual at half past five o'clock in the morning of September 4, 1877. His wife was sure that she did not hear him complain of any illness at this time, or at any time previously for many months. She left him at home on the morning above mentioned, while she went to market. On her return, at about seven o'clock, he was at breakfast, his meal consisting of boiled eggs, milk, and bread. After his breakfast he went out, for what purpose and to what place his wife did not know. In fifteen minutes he was brought back to his house by two men who were strangers to Mrs. C. These men stated that they had found C. lying in the middle of a street in a locality having an ugly reputation. When they first saw him two men were standing over him, who disappeared on their approach. Their statement in this respect was confirmed by a woman who lived in the neighborhood, and who saw the group from her window, but could not identify either of the parties. No one saw any blows struck or heard any outcry. No one could be found who had seen $\mathrm{C}$. from the time he left his house till the time he was found prostrate in the street. C. himself could give only a confused account of his acts. When asked by the two men who assisted him where his home was, he gave the number correctly, but he was unable to explain his condition or the manner of its occurrence. In the course of other talk, incoherent in character, he said, "Johnny Murray struck me;" but other information was not forthcoming. On his arrival at home he lay down, complaining of pain in his side and in his head. He made repeated allusions to this latter pain. Without being specific about it, his utterances led his wife to believe that he had been assaulted. This suspicion was strengthened by neighborhood gossip, which mentioned names of witnesses of the supposed quarrel, but the witnesses themselves, when interrogated, professed ignorance of the entire affair. 
On the day following the alleged assault $C$. complained still more of his head, and vomiting supervened. Thirty-one hours after he was found in the street a convulsion occurred, and now for the first time medical aid was summoned. More convulsions followed, and in three hours and a half the man was dead.

At the instance of the attending physician I was summoned by the police, the presumption being that in some manner not yet clear this man had met his death in consequence of violence. From all the facts then at hand this presumption was a reasonable one; at all events, the case was clearly one demanding investigation. Accordingly, being duly authorized by the district attorney, I made an autopsy, but not without some difficulty, for the widow and her neighbors were much excited, and, though strong in their belief that the man had been murdered, they were emphatically strenuous against a post-mortem examination.

Externally, the body presented the following appearances : over the angle of the right scapula was an ecchymosis of the size of an old-fashioned copper cent. On the posterior aspect of the right arm near the elbow was another bruise an inch by half an inch in diameter. These were the only signs of wounds which a careful external inspection discovered. The regions of the head and neck were particularly examined, but nothing was found as the result of the alleged beating.

Except some indications of former inflammation of the right lung and pleura, the viscera of the chest and abdomen were normal.

Examination of the head revealed the following conditions: The scalp was healthy in all respects; there was no trace of extravasation or lesion indicating a blow. On removing the calvaria and the dura mater the vascular meninges were found to be hyperæmic, especially so on the right side. Within the middle lobe of the right cerebral hemisphere were two clots: one near the base of the brain, with well-defined outline, and having the size of an English walnut; the other a little higher and more posterior, and of about the size of a filbert. The former of these clots had broken through the gray cortex overlying it, and the hæmorrhage had given rise to a diffused coagulum within the meninges and extending from the base to the vertex. The lateral ventricles and other portions of the brain beside those described presented no abnormal appearance.

The cranium was in all respects normal and entire.

Cerebral hæmorrhage was the certified cause of death.

II. The dead body of Dora A. S., a middle-aged Irish woman of loose reputation, was found lying at full length upon the floor of her kitchen, early in the morning of November 26,1877 . When the body was first discovered, two men were seen standing near in the same room, in excited conference. These two men were at once taken into custody by the police, on suspicion, and the medical examiner was summoned. 
On my arrival at the scene, the body was still disposed as it was found; it was lying upon the back, fully clothed. The limbs were straight, and there was no rigor mortis. The surface of the abdomen was still warm. Near the head there was a collection of semi-fluid, dark-colored matter, probably vomitus. Upon the right cheek was a faint ecchymosis. The clothing was soiled by a copious dejection.

Inspection of the room showed much disorder and slovenliness, with some evidences of violence. The table was set with dirty dishes and half-consumed food. In the midst of the dishes was a pint flask containing a few drops of inferior whisky. Two kerosene lamps were on the table: one of these was burning when the body was discovered; the fragments of the chimney belonging to the other were scattered over the table and on the floor. The furniture of the room was disarranged, but none of it was overturned.

Adjoining this kitchen were two sleeping-rooms, the beds in which were much tumbled. On the mattress of one of the beds was a plentiful deposit of dried blood. The furniture in these rooms showed very rough usage.

At an interview with each of the two suspected men at the station-house the following was presented as their version of the affair: The woman had been indulging in a drunken spree during the previous fortnight, obtaining money in various irregular ways and spending it mainly for liquor. One of the men was her paramour; the other was an acquaintance of twenty-four hours whom she had beguiled on the street. This trio, with other parties who happened in, spent the day (Sunday) before the woman's death in a drunken carouse, consuming ale and whisky freely. Late in the evening the paramour went to bed alone, less intoxicated (if I could believe his statement) than his companions. After an interval the other man succumbed, and the woman remained sitting by the table, very drunk. Each of these men persisted in the assertion that they had no quarreling or violence of any kind. The next morning, at seven o'clock, one of them arose and found the woman lying dead on the floor, but still warm. He aroused the other man, and while they were consulting what to do the party was discovered by the rent collector. Both the men stoutly denied any knowledge of the immediate circumstances under which the woman had died, or of the time of her death. The house was in a thickly-settled neighborhood, but none of the neighbors gave any information tending to make the case clear. The character of this locality, however, with the record of the woman and of her companions and the circumstances of her death, so far as they were learned, justified the presumption that violence was an element in the affair; accordingly an autopsy was required and made in farther investigation of the cause of death.

External inspection of the body discovered a number of faint, super- 
ficial ecchymoses with indistinct outlines; the largest of these was in front of the right ear, its dimensions being one and a half inches long by three quarters of an inch wide. Small bruises were found above the left nipple, over the sternum, in the bend of the right elbow, on the abdomen midway between the pubes and umbilicus, and on the right knee. None of these appeared to be recent. The external cavities of the body, the mouth, ears, nose, anus, and vagina, contained nothing abnormal. The scalp on dissection presented no mark of injury or disease. The skull was uninjured. The brain and its membranes were injected to a moderate degree; there was no extravasation of blood, meningeal or cerebral.

Except a small surface at the base of the right lung bound down by old pleuritic adhesions, the lungs were of healthy appearance. The trachea and bronchi were normal. The heart was healthy in all respects. The blood was fluid and of dark color.

The kidneys presented the typical appearances of chronic inflammation; they were lessened in size, their cortices were thin, their capsules were removed with difficulty, leaving the surface granular. Their section showed hyperæmia.

The spleen and intestines were normal. The liver was mottled, dense, and injected.

The uterus was enlarged, and its mucous membrane was hypertrophied and congested.

The stomach was the organ presenting the most noteworthy alteration. Its entire mucous lining showed intense hyperæmia, without erosion at any point; these appearances were most marked at the fundus. The minute disseminated ecchymoses were too numerous and too uniformly spread to be accounted for by digestion or by post-mortem changes. The oesophagus was reddened at its lower extremity, but elsewhere it was unaltered.

The contents of the stomach, the blood, the brain, and the thoracic viscera imparted a distinct alcoholic odor.

In the presence of these post-mortem appearances I felt obliged to exclude the element of viqlence from the cause of death, and to assign to alcohol the principal and immediate blame.

III. Ellen S., thirty years old, a domestic servant in the family of a wealthy and well-known Brookline gentleman, died in Boston, February 5,1878 . She had left her place in Brookline three weeks previously, being at that time somewhat debilitated, and complaining of illdefined but not severe illness. She declined the urgent offers of her mistress to provide medical attendance and nursing for her, and declared her preference to go to some friends in Boston, to remain till she recovered. These friends were poor in circumstances and in reputation, fond of alcohol and of its exhilaration. Ellen stayed at their house a 
week without seeking medical aid. She appeared exhausted, had no appetite, suffered some abdominal pain. At the end of the week she went with another girl to the office of a regular physician, who, however, had been charged a long time ago with some irregular practices; she received from him two prescriptions. This medicine was dispensed by a neighboring druggist who retained the recipes. The physician visited her at her house twice subsequently, on the two days following the office call; at his last visit he informed her that she would be sick some time with fever, and advised her, as she had but little money, to enter the City Hospital. This advice she declined to follow, and he did not see her again.

Through the next five days following this last medical visit Ellen had no physician, but at the end of that time she grew suddenly and alarmingly worse, her symptoms being chills, exquisitely painful abdominal swelling, high fever, vomiting, and great thirst. An irregular practitioner was now called in. He was struck at once by the swollen belly, and, without any vaginal examination, charged his patient with pregnancy, - a charge which she denied. Then, learning that Ellen had a lover who had recently given her some money, and that she had consulted Dr. — , he persisted in his suspicion that he had a case - of criminal abortion on his hands, though there was no hæmorrhage or lochial discharge, and a physical examination was not had. $\mathrm{He}$ conveyed his suspicions to the late mistress of the girl, and occasioned considerable excitement in that lady and in her family. Meanwhile, the patient sank, and died in great distress, and without having at any time or to any person, so far as could be learned, acknowledged any facts giving color to a suspicion of wrong practices, yet dying under conditions that might be, and were, readily formed into a basis for the presumption of such conduct.

Acting in obedience to his convictions, the doctor gave me notice of his case and of his interpretation of it, and demanded an investigation. His peremptory zeal was seconded by the warm appeal of the former employer of the deceased that I would leave nothing undone to bring the offender to justice, or, by a thorough inquiry, clear the dead girl's character of the imputation now resting upon it.

I believed I saw more of zeal than discretion in all this crimination, and did not enter on the case with much expectation of seeing judicial proceedings result. I did, however, realize the facility with which grave charges are sometimes made upon slight foundation in fact, and this instance seemed an example. Because, therefore, it was an official obligation, not less than because a medical examination would probably make clear that which was now obscure, I took charge of the dead body, directed its removal from the keeping of its drunken guardians, and sought, by dissection, for the cause of death. 
This autopsy was made fifty-five hours post mortem. Omitting its details, I may summarize its results as follows : there was abundant evidence, both externally and internally, of general peritonitis, with suppurative exudation. In the right broad ligament of the uterus an abscess had developed, matured, and ruptured, the exceedingly offensive purulent contents having escaped into the abdomen to originate the mischief there. The cavity of this abscess was of the size of a large orange.

The uterus was very slightly enlarged. It showed no appearance whatever of recent impregnation, of disease, or of mechanical injury; its mucous membrane was entirely normal. The vagina, likewise, was healthy.

The stomach and intestines gave no indication of violent treatment, by drugs or otherwise.

The cause of the death was certified to the registrar and to the district attorney as pelvic abscess resulting in general acute peritonitis.

If time and your forbearance permitted, other similar cases might be added to the foregoing; but those related will suffice to illustrate the purpose of this paper. It must be obvious that these three deaths were attended by circumstances which gave them a distinctive and exceptional character. If the testimony of parties claiming to be cognizant of the concomitant facts was to be credited, neither of the three individuals died in consequence of the operation of natural causes simply. Nor was either of the deaths a death by violence simply, according to the ordinary interpretation. They differ, on the one hand, from the instances of sudden death in which the individual, in the midst of his family or friends, expires in the course of nature without a warning; and, on the other hand, the inspection of the bodies furnished no external, unequivocal sign to point the way to a clear medical opinion that violence had been actually used. So that, in the first instance, all these cases, as to the cause of death, lay under great uncertainty. In one respect, indeed, they had a community of character; over all of them rested the suspicion, approaching to a reasonable presumption, that the deceased persons came to death in consequence of unlawful acts on the part of other persons, and this regardless of the unrestrained neighborhood gossip which always speaks the word " murder" glibly and inconsiderately. Specific accusations were indeed expressed, and in one of the cases arrests were made. In two of the cases the attendant lent the weight of his medical opinion in favor of the theory that violence had been done to the persons of the deceased. Now, these elements, once imparted to the cases, could not be excluded off-hand; they required consideration, they compelled attention. These three dead bodies with their equivocal environments might readily present, on that account, 
problems for solution more difficult than they could have done had they been found with their identity and history actually unknown. Cases of this kind, therefore, offer the opportunity for the application of forensic medicine in its highest function; they demand patient investigation, an unbiased judgment, deliberate caution, intelligent search for the truth, judicious reticence. Upon the answer to the question in such instances, "What caused this person's death ?" depend not only individual interests, but in the broadest sense the conservation of public morality and the promotion of justice.

How does the Massachusetts law of 1877 meet these and similar cases? I have intimated that the law possesses special advantages in this regard. Without exhausting the list, let me mention three of these :-

In the first place, the law provides that a purely medical question shall be solved by a medical man, whose conclusions are preliminary to other proceedings in the case. It creates a medical examiner, and demands of him that he shall determine the cause and manner of death, and that alone. It leaves him free to prosecute his inquiries from the medical stand-point simply. It does not hamper him with a complication of functions ; it does not compel him to be a physician, a detective, a constable, a judge, and a juryman, all in one. The question, "Who caused this death?" is not for him ; it is of no concern to him except as it is related immediately to the solution of that other question for the answer to which he is directly responsible, namely, "What caused this death?" $\mathrm{He}$ is not to lose sight of the fact that he is a physician in the employ of his county, to do a physician's work. He has no need or right to embarrass himself with speculations about murder, justifiable homicide, or simple assault. The law thus aims purposely to remove him beyond the influence of bias and the thralldom of technicalities, and makes it his single aim to ascertain the truthful solution of a purely medical problem.

But, secondly, the law does not create this medical examiner and leave him without the requisite facilities and authority for prosecuting his investigations in a strictly medical manner. It makes easy the one method of inquiry which is indispensable, - the necropsy. It interposes such safeguards and checks only as are needed to prevent the abuse of the authority conferred. The machinery is simple, direct in application, effective. There is no circumlocution, no delay in action. The problem and the agent for its solution are brought into immediate relation.

It thus happened, in each of the three cases cited, that the application of the methods provided by the Massachusetts law cleared up at once and authoritatively matters that were involved in much doubt and obscurity; resolved and dismissed the imputation of crime; and by a determination that the cause of death was not by violence at the hands of others fully satisfied the requirements of public order and of justice. 
And this leads us to the third consideration in behalf of the new law, one which you must have already anticipated, namely, that with the medical report in such cases the official investigation comes to an end, save in circumstances exceptional to the last degree. Thus, as all will recognize, the medical examiner is a responsible agent by whose professional knowledge the public treasury and the public comfort and morals constantly profit in that he is a stay to what, under other circumstances, would be unnecessary, expensive, and, possibly, scantalous inquests.

\section{RECENT PROGRESS IN ANATOMY.1}

BY THOMAS UWIGHT, M. D.

Dr. W. Roux ${ }^{2}$ has written a long paper to prove that the subdivisions of the blood-vessels occur according to the laws of hydro-dynamics, and that they are so arranged as to distribute the blood with the least possible expenditure of vital force. The essay is altogether too abstruse for analysis in this report, and is mentioned merely to serve as an introduction to Professor Schwalbe's ${ }^{3}$ paper on the influence of displacements by growth (Wachsthumsverschielungen) on the conformation of the arterial system. Roux admits that it is impossible for the force of a current to occasion vessels to sprout out at right angles to the parent trunk, much more to make them recurrent; nevertheless such forms are very numerous in the adult. The principle, as Schwalbe himself says, is not new. We are all familiar, for instance, with the lengthening out of the spermatic artery as the testis descends, and of the change of relations between the spinal column and cord that goes on after birth, due to the more rapid growth of the former. Schwalbe, however, calls our attention to new points, and most important of all shows how certain peculiarities in one part of the body make probable the existence of others elsewhere. His observations are not sufficiently numerous to be of much value by themselves, but he has the merit of opening a new field, presumably a rich one, for inquiry.

The reader can easily construct a few diagrams that will illustrate the principle involved. Let him draw two parallel vertical lines A B and $C D$, and connect them by a number of transverse ones at right angles to the first two. Let the line $\mathrm{A} \mathrm{B}$ represent an artery, and $\mathrm{C} \mathrm{D}$ a muscle or anything else beside it, and let the transverse lines be branches running from the former to the latter. Now it is evident that if $\mathrm{C} \mathrm{D}$ grows twice as fast at both ends as $\mathrm{A} B$ does, the branches will become divergent, the upper ones running upward, the lower downward. If, on the other hand, A B grows, the faster they will converge,

1 Concluded from page 306.

2 Jenaische Zeitschrift für Naturwissenschaft, Band xii., Heft 2, 1878.

${ }^{8}$ Ibid. 